François Feihl

Alain F. Broccard

\section{Interactions between respiration and systemic hemodynamics. Part II: practical implications in critical care}

Received: 31 October 2007

Accepted: 31 August 2008

Published online: 30 September 2008

(C) Springer-Verlag 2008

The first part of this article is available at: doi:10.1007/s00134-008-1297-z.

\section{F. Feihl}

Division of Clinical Pathophysiology,

University Hospital (CHUV) and Lausanne

University (UNIL), 1011 Lausanne,

Switzerland

\section{A. F. Broccard}

Medical Intensive Care Unit, Regions Hospital Pulmonary and Critical Care Division, Regions Hospital, St Paul,

MN 55101-2595, USA

\section{F. Feihl (®)}

Division de Physiopathologie Clinique, BH10-701, 1011 Lausanne, Switzerland e-mail: Francois.Feihl@chuv.ch

Tel.: +41-21-3141423

Fax: +41-21-3141432

Abstract In Part I of this review, we have covered basic concepts regarding cardiorespiratory interactions. Here, we put this theoretical framework to practical use. We describe mechanisms underlying Kussmaul's sign and pulsus paradoxus. We review the literature on the use of respiratory variations of blood pressure to evaluate volume status.

We show the possibilities of attaining the latter aim by investigating with ultrasonography how the geometry of great veins fluctuates with respiration. We provide a Guytonian analysis of the effects of PEEP on cardiac output. We terminate with some remarks on the potential of positive pressure breathing to induce acute cor pulmonale, and on the cardiovascular mechanisms that at times may underly the failure to wean a patient from the ventilator.

\section{Clinical correlates}

Kussmaul's sign

Kussmaul's sign is a paradoxical increase in RAP during inspiration. Although first described in constrictive pericarditis, it occurs most frequently in severe right-sided heart failure of any cause [1]. Whether due to pericardial constraint or due to dilation of the ventricular chamber to the limit of distensibility, an abnormally high impedance to right ventricular (RV) diastolic filling is a prerequisite for the appearance of Kussmaul's sign. The traditional explanation is that the rigid RV cannot accommodate the inspiratory increase of venous return [1]. However, if venous return increased solely as a response to the fall in intrathoracic pressure (ITP), RAP measured relative to atmosphere could never become elevated above its end-expiratory value (otherwise, venous return would fall, a contradiction in terms) [2]. Work by Takata and colleagues [3] has shown that an absolute requirement for the occurrence of Kussmaul's sign is an inspiratory increase in abdominal pressure, induced by diaphragmatic descent and presumably raising mean systemic filling pressure (MSFP).

\section{Pulsus paradoxus}

In healthy humans breathing spontaneously, the systolic arterial pressure falls slightly (by less than $10 \mathrm{mmHg}$ ) in inspiration. It is now well accepted that this phenomenon reflects an inspiratory fall of left ventricular (LV) stroke volume due to diastolic ventricular interdependence (Part I, Section "Respiration and cardiac function") [4].

As originally described by Kussmaul in 1873, pulsus paradoxus referred to the inspiratory disappearance of the radial pulse in patients with tuberculous pericarditis $[2,5]$. 
In its present definition, this term designates an abnormally large fall $(>10 \mathrm{mmHg})$ in systolic arterial blood pressure during spontaneous inspiration. Pulsus paradoxus is a frequent symptom of cardiac tamponade [6] and acute severe asthma [7, 8]. It may be observed as well in other forms of airway obstruction and in hypovolemia. There are occasional reports of pulsus paradoxus in massive pleural effusion [9], pulmonary embolism [10], anaphylactic shock [11], strangulated diaphragmatic hernia [12], and tricuspid atresia [13].

As already suspected by Dornhorst 50 years ago [14], the main mechanism of pulsus paradoxus in cardiac tamponade is a massive amplification of parallel diastolic ventricular interdependence, due to a much tighter mechanical coupling of the cardiac chambers when compressed within a tense, pressurized pericardium [6]. Thus, pulsus paradoxus in experimental tamponade disappeared following extracorporeal bypass of the RV [15]. Accordingly, pulsus paradoxus is minimal or absent in tamponade associated with atrial septal defect, a condition in which RV and LV fillings are no longer competitive [16]. For somewhat less clear reasons, tamponade may also fail to cause pulsus paradoxus in presence of concomitant LV dysfunction [17].

The mechanism of pulsus paradoxus in acute severe asthma differs somewhat from that in tamponade. Jardin and colleagues [7] studied patients admitted to an intensive care unit for acute severe asthma, using 2D echography and invasive hemodynamic monitoring. They found that exaggerated parallel diastolic interdependence, although clearly present in view of the respiratory changes in ventricular end-diastolic volumes and septal geometry, did not suffice to explain the concomitant pulsus paradoxus, because RV stroke volume appeared to fall, rather than increase in inspiration. They concluded that, with severe hyperinflation of the lung, inspiration augmented RV afterload sufficiently to depress RV output, hence LV preload. In other words, pulsus paradoxus in acute severe asthma is an exaggerated form of series (in addition to parallel) ventricular interdependence (Part I, Section "Respiration and cardiac function").

Respiratory fluctuations of vascular pressures for the evaluation of preload-sensitivity at the bedside

When peripheral perfusion is inadequate, a basic question facing the clinician is whether any improvement is to be expected from expansion of the intravascular volume. This is equivalent to asking whether the heart operates on the steep portion (i.e., preload-sensitive cardiac output), or on the plateau of its function curve (preload-insensitive). Little help can be expected in that respect from single determinations of RAP and pulmonary artery occlusion pressure (PAOP), as provided by the SwanGanz catheter [18-20]. An essential, although not the only

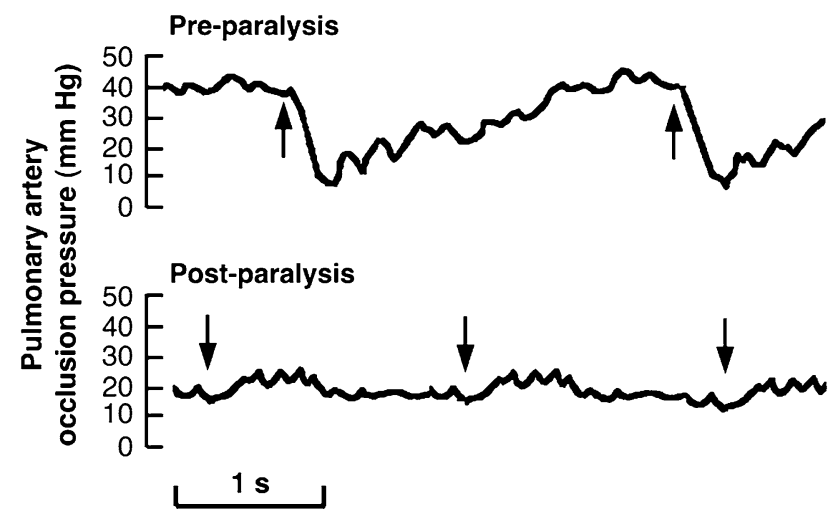

Fig. 1 Impact of active expiration on readings of pulmonary artery occlusion pressure (PAOP) made at end-expiration. In this example obtained in a ventilated patient, the effect is evident from the comparison of recordings made before (upper trace) and after administration of a neuromuscular blocking agent (lower trace). Arrows indicate end-expiration. Before paralysis, active inspiration causes a rapid drop in vascular pressure, the transition from endinspiration to the begin of expiration cannot be recognized, and active expiration is manifested by a progressive increase, reaching a maximum at end-expiration, where the PAOP reads $42 \mathrm{mmHg}$. After paralysis, passive inflation by the ventilator causes the vascular pressure to increase above the end-expiratory value, which now reads $20 \mathrm{mmHg}$. In this case, uncritical reading of the upper trace would lead to considerable overestimation of the true PAOP. The wavelets seen on the upper trace might be cardiogenic oscillations ( $a$ and $v$ waves, compatible with a heart rate of approximately $150 / \mathrm{min}$ ), or artefacts. Modified from [22], with permission

reason is that the PAOP and RAP are intramural rather than true filling (i.e., transmural) pressures [21]. Taking readings at end-expiration is not a foolproof solution, due to frequent active expiration (Fig. 1) [22]. This latter problem may be suspected by abdominal wall palpation to assess for expiratory contraction of abdominal muscles. It may also be detected by observing the respiratory fluctuations of bladder pressure [23]. Also, trends in PAOP and RAP following i.v. fluid administration may be more informative than single measurements [24], an approach which however entails the risk of volume overload. A substitute to fluid challenge devoid of the latter risk might consist in observing the hemodynamic impact of passive leg raising, a maneuver which translocates peripheral blood towards the thorax, and thus may augment cardiac preload [25-27]. Finally, the easily measured respiratory fluctuations of arterial blood pressure and RAP may convey useful information on preload-sensitivity.

In the course of a ventilator-delivered positive pressure breath, the systolic blood pressure transiently increases relative to the stable level obtained in a prolonged expiratory pause (Fig. 2, $\Delta$ up), and then decreases below that level (Fig. 2, $\Delta$ down). The $\Delta$ up reflects the transient augmentation of LV stroke volume related both to diminished afterload and enhanced pulmonary venous return (blood "squeezed out of the lungs") [28-30]. The $\Delta$ down is 


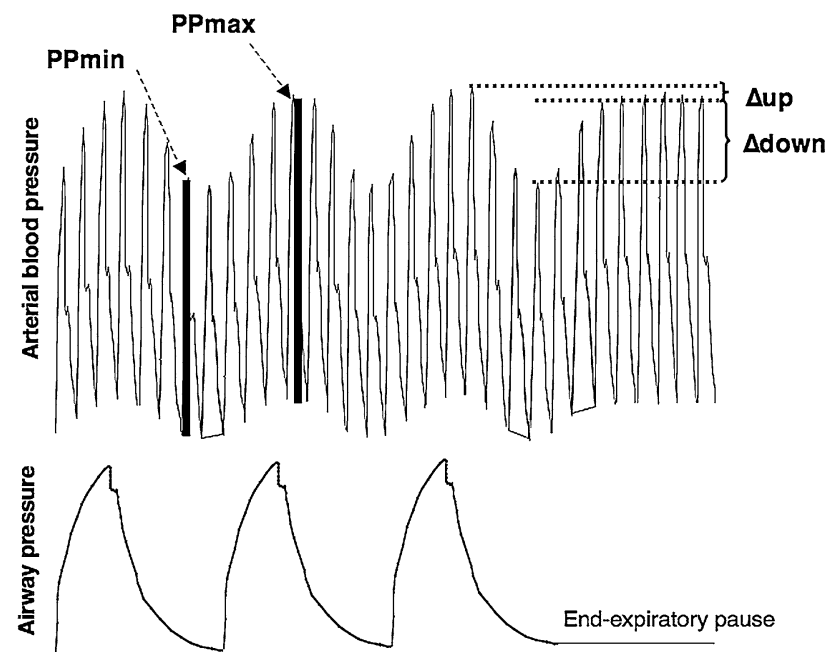

Fig. 2 Respiratory variations of arterial blood pressure in a sedated patient on volume-controlled mechanical ventilation. In such conditions, the respiratory fluctuations of either systolic ( $\Delta$ up and $\Delta$ down) or pulse pressure $\left(\mathrm{PP}_{\max }\right.$ and $\left.\mathrm{PP}_{\min }\right)$ may be used to detect hypovolemia and so determine the need for intravascular volume expansion. The first method requires an end-expiratory pause of sufficient duration for systolic blood pressure to stabilize, to obtain a reference level from which to measure $\Delta$ up and $\Delta$ down as indicated. $\mathrm{PP}_{\max }$ and $\mathrm{PP}_{\min }$ can be obtained without interrupting ventilation. A high value of either $\Delta$ down or $\Delta \mathrm{PP}\left(=\mathrm{PP}_{\max }-\mathrm{PP}_{\min }\right)$ indicates hypovolemia. Detailed explanations in "Respiratory fluctuations of vascular pressures"

caused by the subsequent reduction of LV preload and stroke volume, which takes place in exhalation as the inspiratory depression of RV preload and output propagates to pulmonary venous return with a time lag of a few heartbeats [29]. Thus, preload-insensitivity of the heart should be associated with a blunting or disappearance of the $\Delta$ down. The $\Delta$ up would be less reliable in that respect due to the potential influence of changing LV afterload. This concept has been validated experimentally [31-33]. Two small clinical studies demonstrated a superiority of the $\Delta$ down, compared with either PAOP or echographic estimates of LV size, for predicting the response of cardiac output to a fluid challenge in mechanically ventilated postoperative [34] or severely septic patients [19].

A variation of the $\Delta$ down approach, which has been similarly validated consists in quantifying the variations of pulse pressure $(\triangle \mathrm{PP})$ induced by a positive pressure breath (Fig. 2) [20, 35]. The respiratory fluctuations in the amplitude of the plethysmographic pulse wave (obtained non-invasively from pulse oxymetry) have been used to the same effect [36]. A practical problem with all these methods is the potential confounding influence of cardiac arrythmias, increased abdominal pressure [37], and changes in vascular tone or ventilatory conditions. Indeed, the aforementioned validation studies were carried out in heavily sedated patients ventilated in controlled mode with relatively large tidal volumes $(\geq 8 \mathrm{ml} / \mathrm{kg})[19,20$, 34]. It is not clear that similar results would be obtained with smaller tidal volumes [38-40]. A possible answer to this critique has been proposed in the form of applying a succession of three mechanical breaths of progressively increasing plateau pressure and quantifying the effect on systolic blood pressure [41]. We must finally underscore that these methods lose most of their validity with the presence of active inspiratory or expiratory effort, whether in the course of mechanically assisted or spontaneous breathing $[25,26,42]$.

With spontaneous breathing, Magder et al. [43] have suggested that the lack of an inspiratory drop in RAP is indicative of an overfilled, non-compliant heart lying on the flat part of its function curve, and therefore predicts the lack of volume responsiveness of cardiac output.

\section{Respiratory fluctuations of great veins geometry}

The transmural pressure versus volume relationship of the venae cavae is nonlinear, with a steep slope at low distension and a plateau at full repletion [44]. Thus, one would expect that phasic changes in transmural pressure would more readily translate into respiratory variations in cross-sectional size when imposed on a partially empty vessel (hypovolemia), as opposed to a fully repleted one (normo or hypervolemia). Based on this rationale, the phasic changes in caval diameters, as evaluated from echocardiography, have been proposed as non-invasive indices of intravascular volume status [44-50].

In man, the IVC runs almost entirely intraabdominal, i.e., it enters the right atrium immediately after crossing the diaphragm. Thus, its extramural pressure is abdominal pressure (Pabd), while its intramural pressure lies close to RAP. In the course of a spontaneous inspiration, Pabd increases (diaphragmatic descent) while RAP decreases (transmission of pleural pressure swing), leading to an inspiratory diminution of transmural pressure. The latter, however, only causes the IVC diameter to shrink if the vessel is not fully repleted (i.e., if it operates on the steep part rather than the plateau of its transmural pressure/ diameter relationship). Quantified in various ways with transthoracic echocardiography, the inspiratory decrease of IVC diameter has been used to characterize volume status in the course of hemodialysis for end-stage renal disease $[45,46]$. In the ICU, we are aware of no similar application in spontaneously breathing subjects. In contrast with spontaneous breathing, positive pressure inflation is expected to dilate an incompletely filled IVC, because the positive swing of pleural pressure is fully transmitted to RAP, but only partially to Pabd, thus causing an inspiratory increase of IVC transmural pressure. Two studies have found that the amplitude of phasic changes in IVC geometry, as measured with transthoracic echocardiography, were highly predictive of cardiac output response to a fluid challenge in sedated septic shock patients ventilated in controlled mode [47, 48]. Although 
not documented so far, respiratory fluctuations in IVC diameter are likely to depend not only on volemia, but also on respiratory pattern, prevailing level of mean Pabd, and right ventricular function, as is the case for $\Delta \mathrm{PP}$ and $\Delta$ down.

In contrast to the IVC, the superior vena cava (SVC) runs mainly intrathoracic, so that its extramural pressure is close to pleural pressure. In hypovolemic conditions, positive pressure inflation may transiently create zone 2 conditions (intraluminal pressure $<\mathrm{Ppl}^{1}$ ) in this vessel, leading to its partial inspiratory collapse [49]. Phasic variations of SVC diameter have been found to correlate well with fluid responsiveness of cardiac output in septic patients on controlled mechanical ventilation [50]. This index of hypovolemia has been advocated as superior to that based on IVC diameter [44], notably because it is not influenced by Pabd. In contrast with the IVC, however, the SVC can only be echographically imaged via the transesophageal, but not the transthoracic route.

\section{Effects of PEEP on cardiac output}

The effects of PEEP on cardiac output are modulated by a variety of factors, the understanding of which is greatly facilitated by the Guytonian representation of venous return-cardiac function interactions (i.e., Fig. $2 d$ in Part I). In Fig. 3, the venous return curves labeled "ZEEP" (zero end-expiratory pressure) and "PEEP" have been taken from the data presented above [51] (Fig. 3 in Part I). The venous return curve labeled "PEEP + volume" has been drawn under the assumptions that intravascular volume expansion under PEEP would increase MSFP, with little effect on either Rv or Pcrit (Chapter 12 of [52]). Figure 3a depicts events associated with normal cardiac function: the cardiac function curve under ZEEP is steep (Fig. 4 in Part I) and intersects the corresponding venous return curve at point 1 located slightly on the right of and below the critical point [53]. PEEP effects a shift to the right of the cardiac function curve (Fig. 4, lower left, in Part I) and of the critical point by approximately the same amount (equal to the increase in ITP), while depressing the maximal venous return. Under PEEP, the operating point becomes located on the plateau of the new venous return curve (point 2), showing not only that cardiac output must decrease, but also that it becomes insensitive to changes in cardiac function (point 3 ). In these conditions, volume expansion is mandatory to restore systemic blood flow (point 4), whereas PEEP superimposed on hypovolemia may lead to cardiovascular collapse (point 4a), as is well known to clinicians [54].

Figure $3 \mathrm{~b}$ shows the possible effects of PEEP in presence of LV failure. Under ZEEP, the cardiac function

\footnotetext{
${ }^{1}$ In analogy with West lung zones, see Part I, Section "Respiration and cardiac function; RV afterload".
}

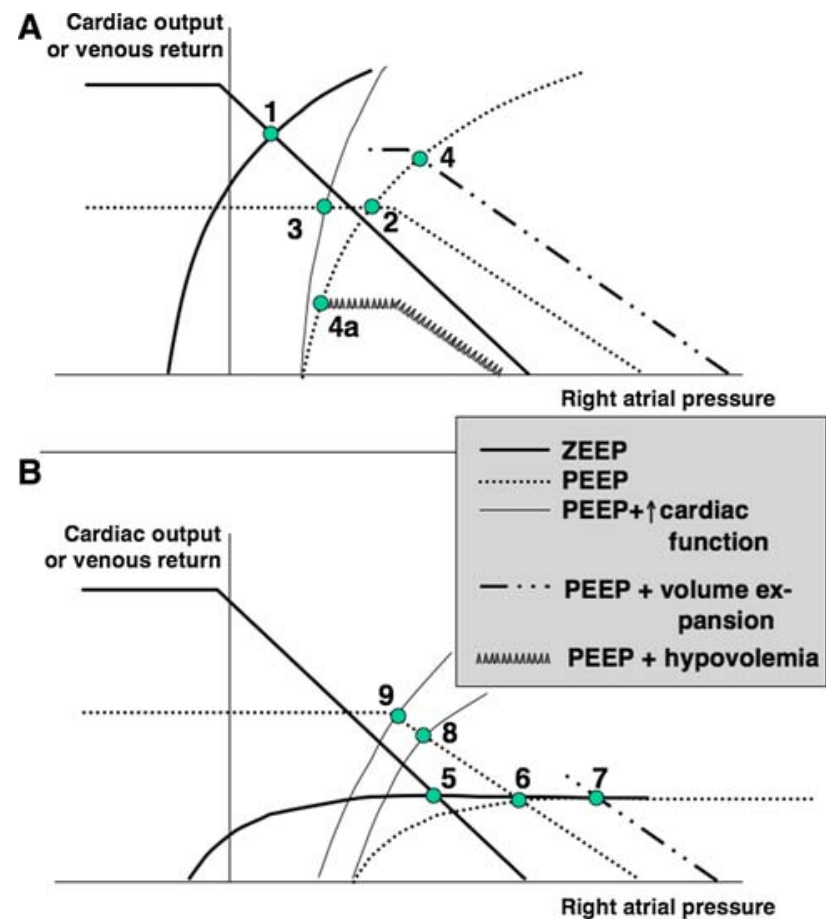

Fig. 3 Various possible effects of PEEP on cardiac output, illustrated with Guyton's graphical analysis: a with normal cardiac function, $\mathbf{b}$ with depressed cardiac function. In both panels $\mathbf{a}$ and $\mathbf{b}$, right atrial pressure is measured relative to atmosphere, i.e., it represents the intracavitary pressure. This is the reason why PEEP shifts the cardiac function curve to the right (see left lower part of Fig. 4 in Part I). PEEP shifts the venous return curve as shown in Fig. 3 of Part I, i.e., the zero flow intercept (which is MSFP) and the critical pressure (Pcrit, at the intersection of the oblique and plateau parts) are increased by approximately equal amounts, while the maximal venous return (height of the plateau part) is depressed. Volume expansion shifts the venous return curve "rightwards" (see Footnote 2 in Part I), whereas hypovolemia has the opposite effect. Pcrit is not affected by changes in volemia. Further explanations in the text ("Effects of PEEP on cardiac output")

curve is so depressed that the operating point is located on its plateau (point 5) and remains so under PEEP if cardiac function is not simultaneously altered, i.e., if the cardiac function curve is merely shifted to the right (point 6). In these conditions, systemic blood flow cannot be increased by volume expansion (point 7). With a failing LV, however, cardiac function becomes sensitive to changes in LV afterload. Reduction of the latter by PEEP or continuous positive airway pressure (CPAP), therefore may cause cardiac output to increase (point 8) $[55,56]$, or at least to be better preserved [57-59] in normo- or hypervolemic patients with a failing left heart, compared to those with normal LV function.

It is worth noting that PEEP reduces the afterload of the failing LV by increasing LV extramural pressure at all phases of the respiratory cycle, not only at end-expiration. This is especially true when spontaneous inspiratory efforts occur in the context of pulmonary edema: PEEP or 
CPAP then improve lung mechanics, thereby attenuating the negative inspiratory swings of ITP [59]. Another interesting observation has been made by Huberfeld and colleagues [60], who found in volume loaded sedated pigs that a substantial surface pressure existed on the dilated heart under ZEEP. Application of CPAP in these conditions decreased pericardial pressure, in spite of increasing esophageal pressure (Fig. 4). This paradox was explained by the lower heart size which followed afterload reduction by CPAP. In Fig. 3b, this phenomenon would translate into a shift to the left of the cardiac function curve, with a further increase in cardiac output (point 9). These considerations form in part the basis for the beneficial hemodynamic effects of CPAP or mechanical ventilation with PEEP in LV failure [59, 61-65]. However, a limit would be set to these benefits by the concomitant reduction of maximal venous return. Accordingly, clinical experience has shown that moderate levels of end-

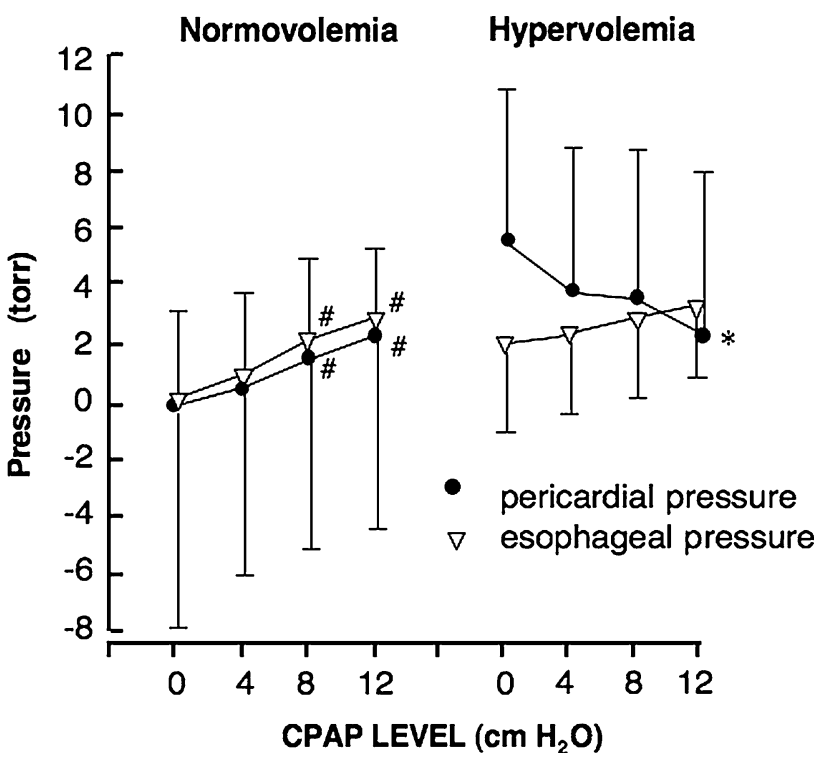

Fig. 4 Differential effects of continuous positive airway pressure (CPAP) on esophageal and pericardial pressure in normovolemic and hypervolemic pigs. Pigs were chronically instrumented with pressure sensors in the pericardial space. On the day of experiment a pressure sensor was inserted into the esophagus. The animals were intubated and connected to a high flow CPAP system. Esophageal (Pes) and pericardial pressure (Pper) were measured synchronously at end-diastole, at various CPAP levels, before (normovolemia) and after volume expansion with i.v. hetastarch (35 ml/kg, hypervolemia). In normovolemia, Pper and Pes track each other. In hypervolemia and without CPAP, Pper exceeds Pes, due to the contact pressure exerted by the lung on the surface of the dilated heart. The progressive institution of CPAP reduces the afterload of the left ventricle (LV), with the following consequences: a smaller LV, a lower global size of the heart, hence release of contact pressure exerted by the lung and finally reduction of Pper. Pes, measured away from the lung surface, increases with CPAP, independent of heart size. From [60], with permission expiratory pressure $\left(5-10 \mathrm{~cm} \mathrm{H}_{2} \mathrm{O}\right)$ are optimal in these conditions.

Of course, Fig. 3 is an oversimplified representation of two idealized extremes in continuous spectrum of actual situations. However, it is certainly necessary to evaluate in each patient whether he/she stands closer to panel A or B. Such evaluation essentially requires integrated clinical and pathophysiological thinking. Some help may come from observing the phasic fluctuations of arterial pressure or great veins geometry (see previous two sections).

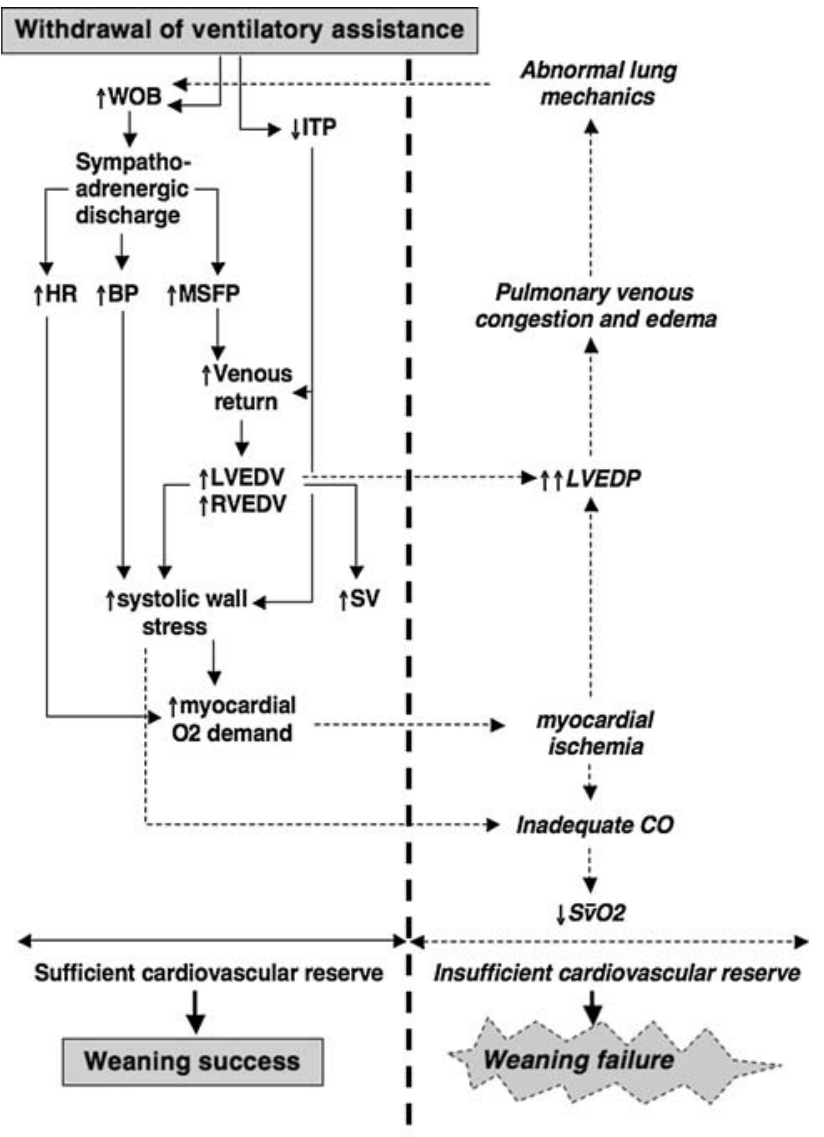

Fig. 5 Cardiovascular mechanisms of weaning failure. The obligatory cardiovascular effects of withdrawing mechanical assistance (linked by plain arrows) are depicted on the left of the thick vertical dashed line. The dashed arrows point to potential consequences in presence of insufficient cardiovascular reserve. $B P$ blood pressure, $C O$ cardiac output, $H R$ heart rate, ITP intrathoracic pressure, $M S F P$ mean systemic filling pressure, $L V E D V$ left ventricular enddiastolic volume, LVEDP left ventricular end-diastolic pressure, $R V E D V$ right ventricular end-diastolic volume, $S V$ stroke volume, $\mathrm{S} \bar{v} \mathrm{O}_{2}$ mixed venous oxygen saturation, $W O B$ work of breathing. Upstream effects on the lung and downstream effects on peripheral oxygenation are not necessarily linked: depending on circumstances, one or the other may predominate, or both may occur concomitantly More explanations in "Weaning failure from cardiovascular origin" 
Mechanical ventilation and acute cor pulmonale

Acute pulmonary hypertension and associated RV failure (acute cor pulmonale, ACP) are frequent findings in patients on mechanical ventilation for respiratory failure, especially ARDS. An important role in this setting is now attributed to mechanical ventilation itself, which in addition to promoting alveolar-capillary injury, acts by direct mechanical augmentation of RV afterload in the inflation period, leading to RV dilation, abnormal septal motion and low cardiac output [66, 67] (Part I, Section "Ventricular afterload"). Especially when combined with high inflation pressures, ACP in ARDS is associated with a high mortality [68]. One might speculate that the improved mortality seen when patients with ARDS receive smaller tidal volumes [69] may be due in part to improved RV function.

It is essential for clinicians to understand that, in patients with ARDS, a major cause of ventilator-induced hypotension may not be venous return impairment but increased RV afterload. Echography is required to confirm this mechanism, and the correct treatment in this case is primarily a reduction in inflation pressures, especially plateau pressure.

Weaning failure from cardiovascular origin

The switch from assisted to spontaneous breathing stresses the cardiovascular system, akin to an exercise test [70]. As depicted in the left part of Fig. 5. weaning activates the sympathoadrenergic system, with predictable consequences on heart rate and blood pressure. Due to venoconstriction and associated reduction in venous compliance, MSFP increases. At the same time, the mean ITP falls, thus increasing LV afterload (Part I, Section "Ventricular afterload"), to which the failing heart is oversensitive. Furthermore, venous return is boosted, leading to increased right and left ventricular end-diastolic volumes. These chains of events augment the myocardial $\mathrm{O}_{2}$ demand. A prerequisite to successful weaning is therefore that the heart be able to cope with this situation. With diminished cardiovascular reserve (right hand part of Fig. 5), myocardial ischemia may appear [71], and left ventricular filling pressure may increase disproportionately [72]. The upstream consequences on the lung [72] and downstream consequences on $\mathrm{O}_{2}$ transport [73] then initiate vicious circles which culminate in florid cardiorespiratory failure and the need to resume mechanical ventilation. Such considerations are of paramount importance when evaluating patients who are difficult to wean [74].

\section{Conclusion}

Cardiorespiratory interactions are encountered daily in the clinical practice of critical care. Much of our understanding in this area rests on fundamental knowledge acquired decades ago. These concepts have then been enriched by technological advance, notably the advent and ever greater performance of echocardiography, and are likely to keep evolving as new methods of investigation become available, such as cardiorespiratoryresolved magnetic resonance imaging [75]. We hope to have convinced the reader that understanding cardiorespiratory interactions is not only of academic, but also of practical importance for his or her training as an intensivist. The concepts covered in the present review are essential to the proper use of mechanical ventilatory assistance. Furthermore, they have been put to use in the last decade in order to promote a less invasive approach to hemodynamic monitoring, an area in which progress may be expected in the near future.

Acknowledgments We warmly thank the reviewers for their contribution to this text, in the form of numerous thoughtful, in depth, and very constructive comments.

\section{References}

1. O'Rourke RA, Silverman ME, Schlant RC (1994) Chap 10: general examination of the patient. In: Schlant RC, Wayne Alexander R (eds) The heart, arteries and veins. McGraw-Hill, New York, p 240

2. Fessler HE (1997) Heart-lung interactions: applications in the critically ill (review). Eur Respir J 10:226-237

3. Takata M, Beloucif S, Shimada M, Robotham JL (1992) Superior and inferior vena caval flows during respiration: pathogenesis of Kussmaul's sign. Am J Physiol 262:H763-H770
4. Scharf SM (1992) Cardiopulmonary interactions. In: Scharf SM (ed) Cardiopulmonary physiology in critical care. Marcel Dekker, New York, pp 333-355

5. Wise RA (1994) Historical perspectives on the mechanical interactions of respiration and circulation. In: Perret $\mathrm{C}$ (ed) Les interactions cardiopulmonaires. Arnette, Paris, pp 3-15

6. Reddy PS, Curtiss EI (1990) Cardiac tamponade. Cardiol Clin 8:627-637
7. Jardin F, Farcot JC, Boisante L, Prost JF, Gueret P, Bourdarias JP (1982) Mechanism of paradoxic pulse in bronchial asthma. Circulation 66:887894

8. Blaustein AS, Risser TA, Weiss JW, Parker JA, Holman BL, McFadden ER (1986) Mechanisms of pulsus paradoxus during resistive respiratory loading and asthma. J Am Coll Cardiol $8: 529-536$ 
9. Vaska K, Wann LS, Sagar K, Klopfenstein HS (1992) Pleural effusion as a cause of right ventricular diastolic collapse. Circulation 86:609617

10. Silverman HJ, Haponik EF (1986)

Pulsus paradoxus in pulmonary embolism: reversal with thrombolytic therapy. Crit Care Med 14:165-166

11. Ward GL, Heiselman DE, White LJ (1992) Pulsus paradoxus in anaphylactic shock due to urokinase administration. Chest 101:589

12. Hooper TL, Lawson RA (1986) Volvulus of the stomach-an unusual cause of pulsus paradoxus. Postgrad Med J 62:377-379

13. Baum VC, Tarnoff H, Hoffman JI (1980) Pulsus paradoxus in a patient with tricuspid atresia and hypoplastic right heart. Circulation 62:651-652

14. Dornhorst AC, Howard P, Leathart GL (1952) Pulsus paradoxus. Lancet 1:746748

15. Shabetai R, Fowler NO, Guntheroth WG (1970) The hemodynamics of cardiac tamponade and constrictive pericarditis. Am J Cardiol 26:480-489

16. Winer HE, Kronzon I (1979) Absence of paradoxical pulse in patients with cardiac tamponade and atrial septal defects. Am J Cardiol 44:378-380

17. Hoit BD, Gabel M, Fowler NO (1990) Cardiac tamponade in left ventricular dysfunction. Circulation 82:1370-1376

18. Diebel L, Wilson RF, Heins J, Larky H, Warsow K, Wilson S (1994) Enddiastolic volume versus pulmonary artery wedge pressure in evaluating cardiac preload in trauma patients. $\mathbf{J}$ Trauma 37:950-955

19. Tavernier B, Makhotine O, Lebuffe G, Dupont J, Scherpereel P (1998) Systolic pressure variation as a guide to fluid therapy in patients with sepsis-induced hypotension. Anesthesiology 89:13131321

20. Michard F, Boussat S, Chemla D, Anguel N, Mercat A, Lecarpentier Y, Richard C, Pinsky MR, Teboul JL (2000) Relation between respiratory changes in arterial pulse pressure and fluid responsiveness in septic patients with acute circulatory failure. Am J Respir Crit Care Med 162:134-138

21. Pinsky MR (2003) Pulmonary artery occlusion pressure. Intensive Care Med 29:19-22

22. Hoyt JD, Leatherman JW (1997) Interpretation of the pulmonary artery occlusion pressure in mechanically ventilated patients with large respiratory excursions in intrathoracic pressure. Intensive Care Med 23:11251131
23. Qureshi AS, Shapiro RS, Leatherman JW (2007) Use of bladder pressure to correct for the effect of expiratory muscle activity on central venous pressure. Intensive Care Med 33:19071912

24. Feihl F, Perret C (1995) Right heart catheterization at bedside: a note of cautious optimism (comment). Intensive Care Med 21:296-298

25. Monnet X, Rienzo M, Osman D, Anguel N, Richard C, Pinsky MR, Teboul JL (2006) Passive leg raising predicts fluid responsiveness in the critically ill. Crit Care Med 34:14021407

26. De Backer D, Pinsky MR (2007) Can one predict fluid responsiveness in spontaneously breathing patients? Intensive Care Med 33:1111-1113

27. Monnet X, Teboul JL (2008) Passive leg raising. Intensive Care Med 34:659663

28. Brower R, Wise RA, Hassapoyannes C, Bromberger-Barnea B, Permutt S (1985) Effect of lung inflation on lung blood volume and pulmonary venous flow. J Appl Physiol 58:954-963

29. Jardin F, Farcot JC, Gueret P, Prost JF, Ozier Y, Bourdarias JP (1983) Cyclic changes in arterial pulse during respiratory support. Circulation 68:266274

30. Vieillard-Baron A, Chergui K, Augarde R, Prin S, Page B, Beauchet A, Jardin F (2003) Cyclic changes in arterial pulse during respiratory support revisited by Doppler echocardiography. Am J Respir Crit Care Med 168:671-676

31. Perel A, Pizov R, Cotev S (1987) Systolic blood pressure variation is a sensitive indicator of hypovolemia in ventilated dogs subjected to graded hemorrhage. Anesthesiology 67:498-502

32. Pizov R, Ya'ari Y, Perel A (1989) The arterial pressure waveform during acute ventricular failure and synchronized external chest compression. Anesth Analg 68:150-156

33. Pizov R, Cohen M, Weiss Y, Segal E, Cotev S, Perel A (1996) Positive endexpiratory pressure-induced hemodynamic changes are reflected in the arterial pressure waveform. Crit Care Med 24:1381-1387

34. Coriat P, Vrillon M, Perel A, Baron JF, Le Bret F, Saada M, Viars P (1994) A comparison of systolic blood pressure variations and echocardiographic estimates of end-diastolic left ventricular size in patients after aortic surgery (see comments). Anesth Analg 78:46-53
35. Michard F, Chemla D, Richard C, Wysocki M, Pinsky MR, Lecarpentier Y, Teboul JL (1999) Clinical use of respiratory changes in arterial pulse pressure to monitor the hemodynamic effects of PEEP. Am J Respir Crit Care Med 159:935-939

36. Feissel M, Teboul JL, Merlani P, Badie J, Faller JP, Bendjelid K (2007) Plethysmographic dynamic indices predict fluid responsiveness in septic ventilated patients. Intensive Care Med 33:993-999

37. Duperret S, Lhuillier F, Piriou V, Vivier E, Metton O, Branche P, Annat G, Bendjelid K, Viale JP (2007) Increased intra-abdominal pressure affects respiratory variations in arterial pressure in normovolaemic and hypovolaemic mechanically ventilated healthy pigs. Intensive Care Med 33:163-171

38. Szold A, Pizov R, Segal E, Perel A (1989) The effect of tidal volume and intravascular volume state on systolic pressure variation in ventilated dogs. Intensive Care Med 15:368-371

39. Reuter DA, Bayerlein J, Goepfert MS, Weis FC, Kilger E, Lamm P, Goetz AE (2003) Influence of tidal volume on left ventricular stroke volume variation measured by pulse contour analysis in mechanically ventilated patients. Intensive Care Med 29:476-480

40. Renner J, Cavus E, Meybohm P, Tonner P, Steinfath M, Scholz J, Lutter G, Bein B (2007) Stroke volume variation during hemorrhage and after fluid loading: impact of different tidal volumes. Acta Anaesthesiol Scand 51:538-544

41. Preisman S, Kogan S, Berkenstadt $H$, Perel A (2005) Predicting fluid responsiveness in patients undergoing cardiac surgery: functional haemodynamic parameters including the Respiratory Systolic Variation Test and static preload indicators. Br J Anaesth 95:746-755

42. Soubrier S, Saulnier F, Hubert H, Delour P, Lenci H, Onimus T, Nseir S, Durocher A (2007) Can dynamic indicators help the prediction of fluid responsiveness in spontaneously breathing critically ill patients? Intensive Care Med 33:1117-1124

43. Magder S, Georgiadis G, Cheong T (1992) Respiratory variations in right atrial pressure predict the response to fluid challenge. J Crit Care 7:76-85

44. Charron C, Caille V, Jardin F, Vieillard-Baron A (2006) Echocardiographic measurement of fluid responsiveness. Curr Opin Crit Care 12:249-254 
45. Mandelbaum A, Ritz E (1996) Vena cava diameter measurement for estimation of dry weight in haemodialysis patients. Nephrol Dial Transplant 11(Suppl 2):24-27

46. Haciomeroglu P, Ozkaya O, Gunal N, Baysal K (2007) Venous collapsibility index changes in children on dialysis. Nephrology (Carlton) 12:135-139

47. Feissel M, Michard F, Faller JP, Teboul JL (2004) The respiratory variation in inferior vena cava diameter as a guide to fluid therapy. Intensive Care Med 30:1834-1837

48. Barbier C, Loubieres Y, Schmit C, Hayon J, Ricome JL, Jardin F, Vieillard-Baron A (2004) Respiratory changes in inferior vena cava diameter are helpful in predicting fluid responsiveness in ventilated septic patients. Intensive Care Med 30:17401746

49. Vieillard-Baron A, Augarde R, Prin S, Page B, Beauchet A, Jardin F (2001) Influence of superior vena caval zone condition on cyclic changes in right ventricular outflow during respiratory support. Anesthesiology 95:1083-1088

50. Vieillard-Baron A, Chergui K, Rabiller A, Peyrouset O, Page B, Beauchet A, Jardin F (2004) Superior vena caval collapsibility as a gauge of volume status in ventilated septic patients. Intensive Care Med 30:1734-1739

51. Fessler HE, Brower RG, Wise RA, Permutt S (1992) Effects of positive end-expiratory pressure on the canine venous return curve. Am Rev Respir Dis 146:4-10

52. Guyton AC, Jones CE, Coleman TG (1973) Circulatory physiology: cardiac output and its regulation. W. B. Saunders Company, Philadelphia

53. Guyton AC (1955) Determination of cardiac output by equating venous return curves with cardiac response curves. Physiol Rev 35:123-129

54. Qvist J, Pontoppidan H, Wilson RS, Lowenstein E, Laver MB (1975) Hemodynamic response to mechanical ventilation with PEEP: the effect of hypervolemia. Anesthesiology 42:4555

55. Grace MP, Greenbaum DM (1982) Cardiac performance in response to PEEP in patients with cardiac dysfunction. Crit Care Med 10:358-360

56. Bradley TD, Holloway RM, McLaughlin PR, Ross BL, Walters J, Liu PP (1992) Cardiac output response to continuous positive airway pressure in congestive heart failure. Am Rev Respir Dis 145(2 Pt 1):377-382
57. Rasanen J, Heikkila J, Downs J, Nikki P, Vaisanen I, Viitanen A (1985) Continuous positive airway pressure by face mask in acute cardiogenic pulmonary edema. Am J Cardiol 55:296-300

58. Naughton MT, Rahman MA, Hara K, Floras JS, Bradley TD (1995) Effect of continuous positive airway pressure on intrathoracic and left ventricular transmural pressures in patients with congestive heart failure. Circulation 91:1725-1731

59. Lenique F, Habis M, Lofaso F, DuboisRande JL, Harf A, Brochard L (1997) Ventilatory and hemodynamic effects of continuous positive airway pressure in left heart failure. Am J Respir Crit Care Med 155:500-505

60. Huberfeld SI, Genovese J, Tarasiuk A, Scharf SM (1995) Effect of CPAP on pericardial pressure and respiratory system mechanics in pigs. Am J Respir Crit Care Med 152:142-147

61. Pinsky MR, Summer WR, Wise RA, Permutt S, Bromberger-Barnea B (1983) Augmentation of cardiac function by elevation of intrathoracic pressure. J Appl Physiol 54:950-955

62. Rasanen J, Vaisanen IT, Heikkila J, Nikki P (1985) Acute myocardial infarction complicated by left ventricular dysfunction and respiratory failure. The effects of continuous positive airway pressure. Chest 87:158162

63. Genovese J, Huberfeld S, Tarasiuk A, Moskowitz M, Scharf SM (1995) Effects of CPAP on cardiac output in pigs with pacing-induced congestive heart failure. Am J Respir Crit Care Med 152:1847-1853

64. Mehta S, Liu PP, Fitzgerald FS, Allidina YK, Douglas Bradley T (2000) Effects of continuous positive airway pressure on cardiac volumes in patients with ischemic and dilated cardiomyopathy. Am J Respir Crit Care Med 161:128-134

65. Scharf SM (2001) Ventilatory support in the failing heart. In: Scharf SM, Pinsky MR, Magder S (eds) Respiratory-circulatory interactions in health and disease. Marcel Dekker, New York, pp 519-550

66. Jardin F, Delorme G, Hardy A, Auvert B, Beauchet A, Bourdarias JP (1990) Reevaluation of hemodynamic consequences of positive pressure ventilation: emphasis on cyclic right ventricular afterloading by mechanical lung inflation. Anesthesiology 72:966970
67. Vieillard-Baron A, Loubieres Y, Schmitt JM, Page B, Dubourg O, Jardin $F$ (1999) Cyclic changes in right ventricular output impedance during mechanical ventilation. J Appl Physiol 87:1644-1650

68. Jardin F, Vieillard-Baron A (2007) Is there a safe plateau pressure in ARDS? The right heart only knows. Intensive Care Med 33:444-447

69. The Acute Respiratory Distress Syndrome Network (2000) Ventilation with lower tidal volumes as compared with traditional tidal volumes for acute lung injury and the acute respiratory distress syndrome. The Acute Respiratory Distress Syndrome Network. N Engl J Med 342:1301-1308

70. Pinsky MR (2000) Breathing as exercise: the cardiovascular response to weaning from mechanical ventilation (comment). Intensive Care Med 26:1164-1166

71. Hurford WE, Lynch KE, Strauss HW, Lowenstein E, Zapol WM (1991) Myocardial perfusion as assessed by thallium-201 scintigraphy during the discontinuation of mechanical ventilation in ventilator-dependent patients. Anesthesiology 74:1007-1016

72. Lemaire F, Teboul JL, Cinotti L, Giotto G, Abrouk F, Steg G, Macquin-Mavier I, Zapol WM (1988) Acute left ventricular dysfunction during unsuccessful weaning from mechanical ventilation. Anesthesiology 69:171-179

73. Jubran A, Mathru M, Dries D, Tobin MJ (1998) Continuous recordings of mixed venous oxygen saturation during weaning from mechanical ventilation and the ramifications thereof. Am J Respir Crit Care Med 158:1763-1769

74. Boles JM, Bion J, Connors A, Herridge M, Marsh B, Melot C, Pearl R, Silverman H, Stanchina M, VieillardBaron A, Welte T (2007) Weaning from mechanical ventilation. Eur Respir J 29:1033-1056

75. Thompson RB, McVeigh ER (2006) Cardiorespiratory-resolved magnetic resonance imaging: measuring respiratory modulation of cardiac function. Magn Reson Med 56:13011310 